\title{
V3-Specific Neutralizing Antibodies in Sera From HIV-1 gp160-immunized Volunteers Block Virus Fusion and Act Synergistically with Human Monoclonal Antibody to the Conformation-dependent CD4 Binding Site of gp120
}

\author{
David C. Montefiori, “ Barney S. Graham, * Jintao Zhou, " Jiying Zhou, * Richard A. Bucco, * David H. Schwartz, \\ Lisa A. Cavacini, ${ }^{\star}$ and Marshall R. Posner, ${ }^{\star}$ and the NIH-NIAID AIDS Vaccine Clinical Trials Network \\ ${ }^{*}$ Departments of Pathology and Medicine, Vanderbilt University School of Medicine, Nashville, Tennessee 37232; ${ }^{\ddagger}$ Division of \\ Hematology/Oncology, Department of Medicine, New England Deaconess Hospital, Harvard Medical School, Boston, Massachusetts \\ 02215; and \$Johns Hopkins School of Hygiene and Public Health and School of Medicine, Baltimore, Maryland 21205
}

\begin{abstract}
Sera from 11 volunteers immunized with a recombinant HIV-1 gp160-expressing vaccinia virus (HIVAC-1e; Oncogen/Bristol-Myers Squibb, Seattle, WA ) and boosted with baculovirusderived rgp160 (VaxSyn; MicroGeneSys, Inc., Meriden, CT) were evaluated for functional serum antibodies and their epitopes. Sera obtained prior to boosting had undetectable HIV1-specific IgG and neutralizing activity, and did not block HIV-1 from binding or fusing to CD4 ${ }^{+}$MT-2 cells. $14 \mathrm{~d}$ after boosting, sera from each volunteer contained HIV-1-specific IgG titers of 1:40 to 1:1,280. Five of these sera also contained neutralizing antibodies, where most or all neutralizing activity was blocked by a synthetic peptide corresponding to amino acids 307-330 of the V3 loop of gp120, indicating that neutralizing antibodies were mostly V3 loop-specific. All sera obtained after boosting contained HIV-1 binding/fusion-inhibition antibodies, and a significant portion of their activity was blocked by the V3 loop peptide, a result consistent with the presence of antibodies against the region of the V3 loop that participates in fusion. Three sera with V3 loop-specific neutralizing and fusion-inhibition antibodies were studied further. In competitive antibody binding experiments, antibodies reactive with the conformation-dependent, CD4 binding site of gp1 20 were undetectable in each serum. When evaluated in combination with a monoclonal antibody to the CD4 binding site of gp120, two sera demonstrated synergism in neutralizing assays, and all three sera demonstrated synergism in binding/fusion-inhibition assays, further indicating that the functional antibodies were primarily V3 loop-specific. The synergism also suggests that a vaccine that elicits strong serum antibody responses to both regions of gp1 20 may improve the potential for inducing protective immunity. (J. Clin. Invest. 1993. 92:840-847.) Key words: acquired immunodeficiency syndrome vaccine $\bullet$ neutralizing antibodies • epitopes
\end{abstract}

\section{Introduction}

Infection by HIV-1 is accompanied by a vigorous and sustained antibody response that ultimately fails to prevent pro-

Address correspondence and reprint requests to Dr. David C. Montefiori, Department of Surgery, Duke University Medical Center, P. O. Box 2926, Durham, NC 27710.

Received for publication 16 October 1992 and in revised form 8 February 1993.

J. Clin. Invest.

(c) The American Society for Clinical Investigation, Inc.

0021-9738/93/08/0840/08 $\$ 2.00$

Volume 92, August 1993, 840-847 gression to AIDS $(1,2)$. A more favorable clinical outcome might be possible if immunity existed prior to infection, as was observed in vaccinated chimpanzees that were protected from infection after experimental inoculation with live HIV-1 (3$5)$. Vaccine protection also has been reported in a number of trials using the simian immunodeficiency virus (SIV) ${ }^{1} / \mathrm{ma}^{-}$ caque model (for review see reference 6). Serum antibody responses might be an important element of vaccine protection because hyper-immune globulin prepared from asymptomatic, seropositive humans or macaques, protected chimpanzees from HIV-1 infection $(7,8)$, and macaques from HIV-2 and SIV infection (9), respectively. Protection from HIV-1 infection has also been observed in chimpanzees that had been passively immunized with a neutralizing human monoclonal antibody (10). Establishing a state of immunity by vaccination which is equal to or surpasses that induced by natural infection will be difficult to achieve using the current subunit vaccines, where HIV-1 antigens are not represented in their native form. These approaches are favored, however, because they pose no risk of infection from the vaccine products.

Correlates of effective antibody responses will be useful when evaluating the potential of candidate vaccines to provide protection. Two serological activities thought to be important correlates of HIV-1 immunity are neutralizing antibodies and antibodies that block the HIV-1 gp120 surface envelope glycoprotein from binding to its cellular receptor, CD4 $(11,12)$. This gp 120 molecule is derived from a precursor gp 160, giving rise also to a transmembrane gp4l (13) which, together with gp 120, participates in fusion of the viral membrane with the cytoplasmic membrane of target cells (14-17). A number of neutralizing regions and epitopes of HIV-1 have been identified, most notably those in the third hypervariable (V3) loop (18) and the CD4 binding site (19-22) of gp120. The V3 loop is often regarded as the principal neutralizing domain and contains multiple linear epitopes, which in most cases elicit typerestricted antibody responses capable of neutralizing only genetically similar isolates $(23,24)$. However, sequences at the tip of the V3 loop might be less variable and elicit broader neutralizing antibodies $(25,26)$. V3 loop-specific antibodies have been shown to interfere with a step involved in fusion, but to have no effect on gp120-CD4 binding $(14,15)$. This is consistent with the results of biochemical and functional studies, where mutations in the V3 loop prevented fusion but not gp120-CD4 binding $(16,17)$. In contrast to antibodies against the V3 loop, antibodies against the CD4 binding site of gp120

1. Abbreviations used in this paper: $\mathrm{CI}$, combination index; $\mathrm{CPE}$, cytopathogenic effect; IFA, immunofluorescence assay; MFI, mean fluorescence intensity; NHS, normal human serum; SIV, simian immunodeficiency virus. TCID 50 , tissue culture infective dose-50. 
recognize conserved, discontinuous conformational epitopes, block gp120-CD4 binding, and neutralize a wider range of isolates (20-22, 27-31). These antibodies seem to appear later in infection (32-35), and have been difficult to generate in immunized animals $(3,4)$.

Recently, a set of broadly cross-reactive, gp120-specific human monoclonal antibodies (humAbs), which block gp120CD4 binding and neutralize diverse strains of HIV-1 in vitro, have been identified $(20,28-30)$. These antibodies recognize a discontinuous, conformation-dependent region overlapping the conserved CD4 binding site of gp120 (21, 31). Interestingly, murine mAbs to the V3-loop increased the magnitude by which the above humAbs bound to the CD4 binding site of gp120 (36, 38). Further, the combination of mAbs to these two sites of the gp1 20 molecule acted in a cooperative or synergistic manner in HIV-1 neutralizing assays (36-39). It might therefore be relevant in the design of HIV-1 vaccines to produce a vaccine that elicits strong serum antibody responses to at least these two regions of the gp120 molecule.

A phase I clinical trial was recently completed in healthy, vaccinia-naive, HIV-seronegative volunteers, who received a gp160 recombinant vaccinia virus (HIVAC-le) and later were boosted with $640 \mu \mathrm{g}$ of purified rgp160 synthesized in insect cells (40). Both immunogens were derived from HIV-1 strain LAV/IIIB. Each of the 12 vaccinees developed strong serum antibody responses 2 wk after boosting, as measured by ELISA and Western blot, and eight developed neutralizing antibodies (40). This vaccine approach is novel in humans, and offers potential benefits because neither vaccine alone produced serum antibody responses of this magnitude (41-43). However, while this represents one of the most effective strategies to date for eliciting serum antibodies to HIV-1 envelope glycoproteins in humans, it is clear that not all sera with HIV-1-specific antibodies were capable of neutralizing the virus or blocking gp120-CD4 binding in vitro $(40,44)$.

To better understand the potential benefits and limitations of sequential immunization with the above products, sera obtained before and after boosting from 11 of the 12 vaccinees described above were evaluated for functional antibody activity directed against linear epitopes within the V3 loop, and against conformational epitopes within the CD4 binding site of gp120. Functional activities included the ability to block viable HIV-1 from binding or fusing to MT-2 cells, and the ability to neutralize HIV-1 in an infection assay. The results demonstrated that the serum neutralizing antibodies were mostly V3 loop-specific, and suggested that an improved antibody response to the CD4 binding site of gp120 might significantly increase the level of neutralizing activity induced by vaccination.

\section{Methods}

Cell lines, viruses and reagents. The $\mathrm{CD}^{+}{ }^{+}$human lymphoblastoid cell lines MT-2 (45) and CEM (obtained from Jean-Claude Chermann, National Institute of Health and Medical Research, Marseille, France), were maintained in culture at $37^{\circ} \mathrm{C}$ in RPMI 1640 containing $12 \%$ heat-inactivated $\left(56^{\circ} \mathrm{C}, 1 \mathrm{~h}\right)$ fetal bovine serum, and $50 \mu \mathrm{g}$ of gentamicin per ml. Stocks of HIV-1 IIIB (obtained from R. C. Gallo, National Cancer Institute, Bethesda, MD) were harvested from chronically infected cultures of CEM cells. Virus-containing culture fluids were clarified of cells by low speed centrifugation and filtration through $0.45-\mu \mathrm{m}$ cellulose-acetate filters (Millipore Corp., Bedford, MA). Virus was quantitated by p 24 immunoassay as described by the supplier (Abbott Diagnostics, North Chicago, IL) and by tissue culture infective dose-50 $\left(\mathrm{TCID}_{50}\right)$ assay as described previously (46). H9/HIV-1 MN cells from Dr. Gallo were provided by the AIDS Research and Reference Reagent Program, AIDS Program, National Institute of Allergy and Infectious Diseases, National Institutes of Health, (ERC Bioservices Corp., Rockville, MD). Peptides corresponding to the V2 region of gp120 (amino acids 254-274), to the V3 loop' of gp120 (amino acids 307-330), and to gp41 (amino acids 579-601) were purchased from Sigma Chemical Co. (St. Louis, MO). Numbering is based on the sequence of HIV-1 IIIB (47). The humAb, F105, and IgG1k, was produced as previously described $(30,31)$. Cell-free supernatant was purified over a protein $\mathrm{G}$ column (Pharmacia LKB Biotechnology Inc., Piscataway, NJ). The antibody was directly labeled using biotin- $N$-hydroxysuccinimide ester (Calbiochem-Novabiochem Corp., San Diego, CA). Sera from HIV-1-infected individuals contained antibodies to all major HIV-1 antigens by Western immunoblot (DuPont Co., Wilmington, DE).

Vaccine study and sera. Volunteers were healthy adults, seronegative for vaccinia and HIV-1. HIVAC-1e was administered using bifurcated needle punctures. Volunteers were boosted 280-650 d later with $640 \mu \mathrm{g}$ of rgp 160 as described (40). Sera were obtained from 11 of 12 volunteers at 220 or $14 \mathrm{~d}$ prior to boosting, and again at $14 \mathrm{~d}$ after boosting. Sera from the remaining volunteer were unavailable for study. The recombinant vaccinia virus, v-envNY5 (HIVAC-le; Oncogen/Bristol-Myers Squibb, Seattle, WA), contained the entire coding sequence of gp160 from the LAV/IIIB strain of HIV-1 (48). It was constructed from a vaccinia virus obtained from a commercial preparation of smallpox vaccine (Dryvax; Wyeth Laboratories Philadelphia, PA). Purified rgp160 (VaxSyn), also derived from the LAV/IIIB strain of HIV-1, was developed by MicroGeneSys, Inc., Meriden, CT. It was purified from cell lysates after expression by a recombinant baculovirus in Spodoptera fugipoda cells as described (49).

Immunofluorescence assay (IFA) antibody titers. Antibodies to viral antigens were quantitated by IFA using CEM cells that were recently infected with HIV-1 IIIB, and where $>80 \%$ of cells were antigen positive. Slides of fixed, infected cells were prepared by air-drying and fixing in a 1:1 mixture of acetone/methanol for $30 \mathrm{~min}$. Sera were diluted in PBS containing $0.1 \%$ globin-free BSA (PBS-0.1\% BSA) and incubated on slides for $30 \mathrm{~min}$ at $36^{\circ} \mathrm{C}$ and $100 \%$ humidity. After two washes in carbonate buffer $\left(0.11 \mathrm{M} \mathrm{Na}_{2} \mathrm{CO}_{3}, 0.4 \mathrm{M} \mathrm{NaHCO}_{3}, 0.15 \mathrm{M}\right.$ $\mathrm{NaCl}, 0.05 \%$ Tween- 80 ), the slides were incubated for $30 \mathrm{~min}$ at $36^{\circ} \mathrm{C}$ and $100 \%$ humidity with a 1:200 dilution of fluorescein-conjugated, IgG fraction of goat anti-human IgG (heavy and light chains specific; Cappel Laboratories, Cochranville, PA) containing Evan's blue counter stain. Slides were again washed twice in carbonate buffer, and then mounted using $50 \%$ glycerol and examined for fluorescence using a fluorescence microscope (DIAPHOT-TMD-EF; Nikon Inc., Melville, NY). Antibody titers are defined as the last dilution yielding positive fluorescence.

Competitive binding assay for antibodies reactive with the F105 epitope. Inhibition of binding of biotin-labeled F105 to HIV-1-infected cells by serum antibody was measured by flow cytometry. HIV-1-infected cells were incubated for $30 \mathrm{~min}$ at $4^{\circ} \mathrm{C}$ with sera diluted 1:50, followed by washing with cold PBS. Cells were then incubated with biotin-labeled F105 for $30 \mathrm{~min}$ at $4^{\circ} \mathrm{C}$, washed with PBS, and incubated with FITC-conjugated Streptavidin (Caltag Labs, San Francisco, CA). After a 30 -min incubation at $4^{\circ} \mathrm{C}$, cells were washed and fixed with $1 \%$ paraformaldehyde. As a negative control, HIV-1 infected cells were incubated in normal human serum (NHS) diluted 1:50 followed by staining with labeled F105. Purified F105 $\left(2 \mu \mathrm{g} / 10^{6}\right.$ cells $)$ diluted in NHS (1:50) was used as a positive control. Dependent on the experiment, this concentration of F105 resulted in $15-45 \%$ inhibition of labeled F105 binding to cells. Samples were acquired on a FACScan ${ }^{\circledR}$ (Becton-Dickinson Co., Franklin Lakes, NJ) and analyzed using LYSYS II software to determine mean fluorescence intensity $(M F I)$. Percent inhibition was determined by the formula: [(F105 $M F I_{\mathrm{NHS}}$ - F105 $\left.M F I_{\text {HIV-1 serum }}\right) /\left(\right.$ F105 $\left.\left.M F I_{\text {NHS }}\right)\right] \times 100$. Total serum antibody 
reactivity was titered on HIV-1-infected cells by incubation with serial dilutions of HIV-1 sera for $30 \mathrm{~min}$ at $4^{\circ} \mathrm{C}$. After washing, the cells were stained with FITC-labeled, goat $F\left(a b^{\prime}\right)_{2}$ anti-human IgG, Fc specific (Tago, Inc., Burlingame, CA). Cells were fixed and acquired on a FACScan ${ }^{\star}$ with analysis using LYSYS II software.

Neutralizing antibody assay. HIV-1 IIIB neutralizing antibodies were measured in an MT-2 cell infection assay in 96-well plates as previously described (46). Briefly, twofold dilutions of heat-inactivated $\left(56^{\circ} \mathrm{C}, 1 \mathrm{~h}\right)$ sera were made in triplicate in a total of $100 \mu$ growth medium per well. $50 \mu \mathrm{l}$ of virus $\left(5 \times 10^{4} \mathrm{TCID}_{50}\right.$ of HIV-1 IIIB) were added to all wells except for 1 row of cell control wells, which received growth medium in place of virus. Virus and sera were incubated together for $1 \mathrm{~h}$ at $37^{\circ} \mathrm{C}$. MT-2 cells $\left(5 \times 10^{4}\right.$ in $100 \mu$ l of growth medium) were then added to each well. Viable cells were quantitated colorimetrically by vital dye (neutral red) uptake $3 \mathrm{~d}$ later. Neutral red uptake is a linear function of cell viability, where light absorption at $540 \mathrm{~nm}$ wavelength is linear from 0.025 to 0.85 , corresponding to $2 \times 10^{4}$ to 25 $\times 10^{4}$ viable cells/well in this assay (46). Percent protection was defined as the difference in absorption between test wells (cells + serum + virus) and virus control wells (cells + virus) divided by the difference in absorption between cell control wells (cells only) and virus control wells. Plates were processed for staining when $>70 \%$ cytopathogenic effect (CPE) was present in the virus control wells. Neutralizing titers are the reciprocal of the last dilution to provide at least $45 \%$ protection. The concentration of virus in the inoculum was determined by titration on MT-2 cells using serial threefold dilutions of virus made in sets of eight wells per dilution. The reciprocal dilution at which cells in at least half the wells showed cytopathic effects after 2 wk defined the titer (1 TCID $_{50}$ ).

HIV-I binding/fusion-inhibition assay. Antibodies were examined for an ability to block whole virus from binding or fusing to viable, CD4-positive MT-2 cells. Here, cell-free HIV-1 IIIB (2,500 pg p24) was incubated with vaccine serum in growth medium for a total volume of $250 \mu \mathrm{l}$ at $37^{\circ} \mathrm{C}$ for $30 \mathrm{~min}$. A control set of reactions contained growth medium in place of serum. MT-2 cells $\left(3.75 \times 10^{6}\right.$ in $250 \mu \mathrm{l}$ of growth medium) were added and the mixtures incubated at room temperature for $2 \mathrm{~h}$ with constant gentle mixing. Unbound and loosely bound virus particles were removed by three washes with $5 \mathrm{ml}$ of growth medium. Cell pellets were lysed in $0.5 \mathrm{ml}$ of $0.5 \%$ Triton X-100, debris was removed by brief centrifugation, and p24 antigen was quantitated by immunoassay (Abbott Laboratories) as described by the supplier. All HIV-1 binding/fusion assays were done in duplicate and p24 values averaged. Duplicate samples rarely varied by more than $5 \%$. Values are given as the percent of binding/fusion that was blocked, where total unblocked binding/fusion activity yielded $170-190 \mathrm{pg} \mathrm{p} 24 / \mathrm{ml}$ of cellassociated virus, depending on the experiment. A stock suspension of viral particles used for all experiments was prepared as described above and stored at $-70^{\circ} \mathrm{C}$ in $0.6-\mathrm{ml}$ aliquots. Each time an experiment was to be performed, an aliquot of virus was thawed in a room temperature water bath and diluted 1:5 with growth medium. $125 \mu$ l of diluted virus $(2,500 \mathrm{pg}$ p24) was used in each reaction.

Calculation of synergism, additiveness, and antagonism. Sera from vaccinated volunteers were evaluated in combination with F105 for neutralization and binding/fusion-inhibition activity. Neutralization was measured as described above, except that eight twofold dilutions of a serum sample and F105, alone and in combination, were made on a single plate. For binding/fusion-inhibition activity, four dilutions of each serum sample and F105 were evaluated separately and in combination. Mathematical calculations were performed using the computer program of Chou and Chou (50), which is based on the equations of Chou and Talalay (51). The combination index is defined:

$C I=\frac{(D)_{1}}{(D x)_{1}}+\frac{(D)_{2}}{(D x)_{2}}+\frac{\alpha(D)_{1}(D)_{2}}{(D x)_{1}(D x)_{2}}$

where $C I$ is the combination index, $(D x)_{1}$ is the dose of agent 1 required to produce $x$ percent effect alone, and $(D)_{1}$ is the dose of agent 1 required to produce the same $x$ percent effect in combination with
$(D)_{2}$. The values of $(D x)_{2}$ and $(D)_{2}$ are similarly derived for agent 2 . The value of $\alpha$ is determined from the plot of the dose-effect curve using the median effect equation, $f a / f u=(D / D m)^{m}$, where $f a$ is the fraction affected by dose $D$, $f u$ is the unaffected fraction, $D m$ is the dose required for $50 \%$ effect, and $m$ is the slope of the dose-effect curve. For mutually exclusive antibodies (i.e., similar modes of action ), both antibodies alone and their mixture should give parallel lines in the median effect plot. Mutually nonexclusive antibodies (i.e., independent modes of action), should give parallel lines in the median effect plot but in mixture will give a concave upward curve. If antibodies are mutually exclusive, $\alpha$ is 0 , and if they are mutually nonexclusive, $\alpha$ is $1 . C I$ values of $<1$ indicate synergy, values $>1$ indicate antagonism, and values equal to 1 indicate additive effects.

\section{Results}

HIV-1-specific IgG and neutralizing antibodies present before and after boosting. HIV-1-specific IgG and neutralizing antibodies were measured in sera obtained either $220 \mathrm{~d}$ ( visit 10) or $14 \mathrm{~d}$ ( visit 13) before boosting, depending on by which visit the samples were available for testing. They also were measured in sera obtained $14 \mathrm{~d}$ (visit 15 ) after boosting for all volunteers. The data are shown in Table I. HIV-1-specific IgG was present in only one sample (A17) prior to boosting, where IgG was detected at a 1:20 dilution of serum. Neutralizing antibodies were undetectable prior to boosting.

After boosting, moderate to high titers of HIV-1-specific IgG were detected by IFA, where titers ranged from 1:40 to $1: 1,280$ and had an average titer of $1: 585(S D=1: 460)$. Higher titers of HIV-1 IgG were detected in sera from infected individuals, but it should be remembered that these titers represent antibodies to all major HIV-1 antigens. Also after boosting, neutralizing antibodies were detected in sera from five volunteers. These individuals had titers of HIV-1-specific IgG of $1: 320$ or greater. No neutralizing antibodies were detected in sera with an HIV-1-specific IgG titer less than 1:320. Neutralizing titers ranged from 1:48 to 1:128 and did not seem to correlate with titers of HIV-1-specific IgG because samples with an IgG titer of 1:320 (A12) and 1:640 (A2) and 1:1,280 (A27) had no detectable neutralizing antibodies.

Antibodies which block HIV-1 from binding or fusing to $M T-2$ cells. The binding/fusion-inhibition assay was standardized by establishing the linear range of virus particles found attached to MT-2 cells using a fixed number of cells. This was done using viral suspensions containing from 976 to $31,250 \mathrm{pg}$ of $\mathrm{p} 24 / \mathrm{ml}$. The quantity of cell-associated virus was linear over the entire range of viral concentrations tested (Fig. 1). A viral suspension equal to $2,500 \mathrm{pg}$ p24/reaction was chosen for all subsequent assays because this concentration produced 170$190 \mathrm{pg} \mathrm{p} 24 / \mathrm{ml}$ of cell-associated virus particles. Because the p24 immunoassay was linear from 6 to $200 \mathrm{pg} \mathrm{p} 24 / \mathrm{ml}$, these conditions allowed all p24 determinations to be performed on undiluted samples, saving expensive reagents and time, and adding to consistency. In fact, the same experiment performed at different times by the same person or by different individuals yielded highly reproducible results. The stock suspension of viral particles used in all assays contained no detectable, nonvirus-associated p24 at the dilution used, where non-viral-associated p 24 was sought by excluding Triton X-100 from the p24 immunoassay. This, together with the fact that envelope glycoprotein-specific antibodies in sera from vaccinated volunteers blocked binding or fusion (Table I), indicated that the 
Table I. HIV-1-specific IgG, Neutralizing and Binding/FusionInhibition Antibodies, and Competition of Binding/FusionInhibition Antibodies with a V3 Loop Peptide

\begin{tabular}{|c|c|c|c|c|}
\hline \multirow[b]{2}{*}{ Serum $^{\ddagger}$} & \multirow[b]{2}{*}{$\operatorname{lgG}^{3}$} & \multirow{2}{*}{$\begin{array}{c}\text { Neutralizing } \\
\text { titer" }\end{array}$} & \multicolumn{2}{|c|}{$\begin{array}{l}\text { Percent inhibition of } \\
\text { binding/fusion* }\end{array}$} \\
\hline & & & $-\mathrm{V} 3$ pep & $+V 3$ pep \\
\hline \multicolumn{5}{|l|}{ Vaccinees } \\
\hline A1 v13 & $<20$ & NT & 18 & $\mathrm{NT}^{\mathbf{9}}$ \\
\hline $\mathrm{v} 15$ & 320 & 48 & 36 & $30(17)$ \\
\hline A2 v13 & $<20$ & NT & 8 & NT \\
\hline v15 & 640 & $<24$ & 50 & $27(46)$ \\
\hline A 10 v13 & $<20$ & $<16$ & 9 & NT \\
\hline $\mathrm{v} 15$ & 160 & $<16$ & 52 & $16(69)$ \\
\hline A 12 v13 & $<20$ & $<16$ & 14 & NT \\
\hline v15 & 320 & $<16$ & 45 & $14(69)$ \\
\hline A 15 v13 & $<20$ & $<16$ & 25 & NT \\
\hline v15 & 160 & $<16$ & 36 & $16(56)$ \\
\hline A 17 v10 & 20 & NT & 13 & NT \\
\hline v15 & 1,280 & 48 & 70 & $16(77)$ \\
\hline A 20 v13 & $<20$ & $<16$ & 18 & NT \\
\hline v15 & 640 & 128 & 90 & $25(72)$ \\
\hline A22 v10 & $<20$ & NT & 16 & NT \\
\hline v15 & 1,280 & 48 & 94 & $40(57)$ \\
\hline A27 v10 & $<20$ & NT & 7 & NT \\
\hline v15 & 1,280 & $<24$ & 32 & $7(78)$ \\
\hline A28 v13 & $<20$ & NT & 5 & NT \\
\hline v15 & 320 & 96 & 47 & $24(49)$ \\
\hline A29 v13 & $<20$ & NT & 13 & NT \\
\hline v15 & 40 & $<24$ & 26 & $16(38)$ \\
\hline \multicolumn{5}{|c|}{ Infected patients } \\
\hline P031 & $>5,120$ & 128 & 53 & $24(55)$ \\
\hline P064 & 2,560 & 64 & 85 & $67(21)$ \\
\hline P070 & 2,560 & 64 & 78 & $72(8)$ \\
\hline P074 & 2,560 & 128 & 83 & $76(8)$ \\
\hline
\end{tabular}

* Binding/fusion-inhibition assays were performed at a 1:16 dilution of serum with virus prior to adding cells. As negative controls, sera from six different seronegative individuals were evaluated for binding/fusion-inhibition activity. The range of activity for these six sera was $0-16 \%$ inhibition with a mean of $9.5 \% \pm 6.3 \%$ SD. A V3-loop peptide (V3 pep) was comprised of amino acids 307-330 of the V3 loop of gp120. The peptide was present at $10 \mu \mathrm{g} / \mathrm{ml}$ and had no direct effect on binding/fusion by itself. Values in parentheses represent the percent of binding/fusion-inhibition activity that was blocked by the V3-loop peptide.

‡ Sera from vaccinees were obtained before (visits 10 and 13) or $14 \mathrm{~d}$ after (visit 15) rgp160 boosting.

${ }^{\S} \mathrm{HIV}$-1-specific IgG was measured by indirect immunofluorescence of fixed, CEM/IIIB cells. Titers are given as the reciprocal of the last dilution where fluorescence was detected by fluorescence microscopy. "Titers of neutralizing antibodies are given as the reciprocal serum dilution at which a $45 \%$ or greater reduction in HIV-1-induced cytopathicity was observed.

'NT, not tested.

assay measured the binding or fusion of whole virus particles and not the binding of free p24, or of p24 immune complexes.

Sera obtained prior to boosting contained low levels of HIV-1 binding/fusion-inhibition activity (Table I), which was probably due to background inhibition because up to $16 \%$ activ-

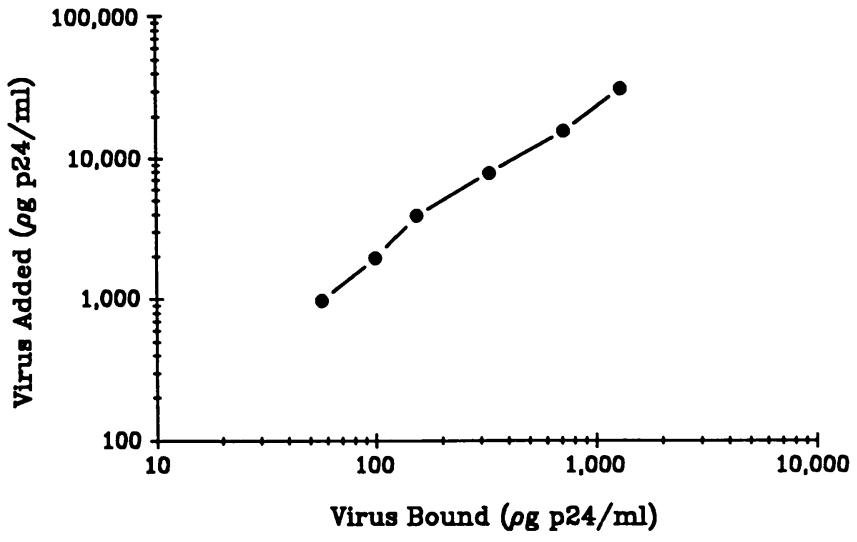

Figure 1. Concentration-dependent attachment of HIV-1 to MT-2 cells. Binding/fusion assays were performed using $1.5 \times 10^{7} \mathrm{MT}-2$ cells/ml and suspensions of HIV-1 IIIB containing from 976 to $31,250 \mathrm{pg} \mathrm{p} 24 / \mathrm{ml}$ in a total vol of $0.5 \mathrm{ml}$ as described in Methods.

ity has been observed for control sera from HIV-1-negative individuals ( Table I, footnote *). After boosting, HIV-1 binding/fusion-inhibition activity increased in sera from each volunteer. The increase in several cases was dramatic, where $50 \%$ or greater inhibition was observed by five sera. The addition of a synthetic peptide corresponding to the V3 loop of gp120 (amino acids 307-330) reduced the activity of all postboost sera (Table I), where the mean reduction of activity was $57 \% \pm$ a SD of $19 \%(n=11)$. In 6 of 11 sera, the activity was reduced to background levels, indicating that most or all binding/fusion-inhibition activity was V3 loop-specific. The V3 loop peptide had much less of an effect on the binding/fusioninhibition activity of antibodies in sera from HIV-1-infected individuals, where the mean reduction of activity was $23 \% \pm$ a SD of $22 \%(n=4)$. Peptides corresponding to amino acids 254-274 (i.e., V2 peptide) and to amino acids 579-601 (i.e., gp41 peptide) of the gp160 molecule had no effect on one of the most potent sera evaluated (i.e., A20, visit 15). Further, none of the peptides at the concentrations used had an effect on HIV-1 binding or fusion by themselves. These results indicate that the V3 loop peptide specifically competed with HIV-1 binding/fusion-inhibition antibodies.

$V 3$ specificity of neutralizing antibodies. The gp160 synthetic peptides were further evaluated for an ability to compete for neutralizing antibodies. Four sera with neutralizing antibodies were preincubated with each peptide $(10 \mu \mathrm{g} / \mathrm{ml})$ and then examined for HIV-1 IIIB neutralizing activity. The results are shown in Table II. Preincubation of sera with the V3 loop peptide completely abolished the neutralizing activity of sera from volunteers A17 and A20, and eliminated most of the neutralizing activity of sera from volunteers A22 and A28. In contrast, the V2 peptide and the gp4 1 peptide had no effect on neutralization. None of the peptides had an effect on infectivity in the absence of neutralizing serum (data not shown).

Absence of antibodies to the CD4 binding site of $\mathrm{gp} 120 \mathrm{rec}$ ognized by $F 105$. Of the four sera in which neutralizing activity was shown to be primarily V3 loop-specific, three (i.e., A17, A20, and A28) were evaluated for antibodies to the CD4 binding site of gp 120 recognized by F105. Sufficient serum from the fourth individual (i.e., A22) was not available for testing. One method by which antibodies to the CD4 binding site were evaluated was to examine each serum's ability to compete with bio- 
Table II. V3 Loop Specificity of Neutralizing Antibodies

\begin{tabular}{ccccc}
\hline & \multicolumn{4}{c}{ Percent protection from HIV-1-induced CPE in presence of } \\
\cline { 2 - 5 } Serum & $\begin{array}{c}\text { No } \\
\text { peptide }\end{array}$ & aa254-274 & aa307-330 & aa579-601 \\
\hline A17 & $61 \pm 5$ & $55 \pm 6$ & 0 & $63 \pm 1$ \\
A20 & $70 \pm 4$ & $70 \pm 2$ & 0 & $54 \pm 4$ \\
A22 & $73 \pm 3$ & $73 \pm 5$ & $3 \pm 6$ & $80 \pm 7$ \\
A28 & $79 \pm 5$ & $81 \pm 3$ & $10 \pm 1$ & $78 \pm 3$ \\
\hline
\end{tabular}

All sera were from visit 15 (i.e., $14 \mathrm{~d}$ after boosting) and were present at a 1:40 dilution. Percent protection from HIV-1-induced cytopathicity was calculated as described in Methods.

Peptides were present at $10 \mu \mathrm{g} / \mathrm{ml}$. The peptides alone had no cell toxicity and provided no antiviral activity.

tin-labeled F105 for binding to $\mathrm{H} 9$ cells chronically infected with HIV-1 IIIB or MN. Before doing this, the reactivity of each serum with the surface of infected cells was determined (Table III). Each serum reacted with a majority $(>80 \%)$ of HIV-1 IIIB cells and had end-point titers of 1,600-6,400. Their reactivity with HIV-1 MN-infected cells was considerably lower, where fewer cells stained positive and end-point titers were much lower. In competition experiments, unlabeled F105 $(2 \mu \mathrm{g} / \mathrm{ml})$ blocked $36 \%$ and $16 \%$ of biotin-labeled F105 from binding to the surface of cells infected with HIV-1 IIIB and MN, respectively (Table III). In comparison, neutralizing sera from vaccinated volunteers were unable to compete with biotin-labeled F105 for binding (Table III).

Synergism between F105 and sera from vaccinated volunteers for HIV-1 neutralization and binding/fusion-inhibition activity. Another method by which antibodies to the CD4 binding site of gp 120 were sought was to evaluate their HIV-1 binding/fusion-inhibition and neutralizing activity in combination with F105, where their presence would be expected to produce an additive effect. On the other hand, because antibodies to the V3 loop are known to enhance the activity of antibodies to the CD4 binding site of gp120 (36-39), a synergistic effect would

Table III. Competitive Binding Experiments for Detecting Antibodies Reactive With the CD4 Binding Region of gpl20 Recognized by F105

\begin{tabular}{|c|c|c|c|c|c|c|}
\hline \multirow[b]{2}{*}{ Serum } & \multicolumn{2}{|c|}{$\begin{array}{c}\text { End-point } \\
\text { titer* }\end{array}$} & \multicolumn{2}{|c|}{$\begin{array}{c}\begin{array}{c}\text { Percentage of } \\
\text { cells }\end{array} \\
\text { staining positive }^{*} \\
\end{array}$} & \multicolumn{2}{|c|}{$\begin{array}{c}\text { Percentage of } \\
\text { F105 } \\
\text { blocked }^{5} \\
\end{array}$} \\
\hline & IIIB & MN & IIIB & MN & IIIB & MN \\
\hline F105 & NA & NA & 97 & 64 & 36 & 16 \\
\hline A17 & 1600 & 100 & 82 & 14 & 0 & 0 \\
\hline A20 & 1600 & 400 & 96 & 54 & 0 & 0 \\
\hline A28 & 6400 & 200 & 99 & 13 & 0 & 0 \\
\hline
\end{tabular}

\footnotetext{
* End-point titers are the last dilution giving a positive signal by flow cytometry after staining infected cells.

${ }^{\ddagger}$ Percent of cells staining positive with a 1:50 dilution of serum. F105 was used at $2 \mu \mathrm{g} / \mathrm{ml}$.

${ }^{8}$ Reduction in mean fluorescence intensity of IIIB-infected cells stained with biotinylated F105 after preincubation of the cells with a 1:50 dilution of vaccine serum. F105 was used at $2 \mu \mathrm{g} / \mathrm{ml}$.
}

be expected if functional antibodies to the CD4 binding site were not well represented in vaccinee's sera. Neutralization was measured at eight dilutions of each serum and F105, alone and in combination. Similarly, HIV-1 binding/fusion-inhibition activity was measured at four dilutions of each serum and humAb F105. Each combination produced greater neutralizing and HIV-1 binding/fusion-inhibition activity than was present for each serum or F105 individually (Fig. 2). The slopes of the curves were evaluated by the method of Chou and Chou (50) for synergism, additive effects, and antagonism at $50 \%$ activity. The data is shown in Table IV. Each combination proved synergistic for HIV-1 binding/fusion-inhibition activity, and two of three sera (i.e., A17 and A28) were synergistic with F105 for neutralizing activity. One serum (i.e., A20), that failed to demonstrate synergism in the neutralization assay appeared to be additive, or possibly mildly antagonistic with F105.

\section{Discussion}

The extensive genetic and antigenic variation exhibited by HIV-1, together with the nature of this virus to integrate its genome into that of infected cells and remain clinically latent for long periods, undoubtedly will make effective vaccination a formidable task. Preliminary studies in animal models of AIDS have provided evidence that vaccine protection is possible under a restricted set of conditions (3-6). Further, passive immunization studies in these animal models have yielded evidence that serum antibodies will make an important contribution to protection (7-10). It is critical to define the correlates of immunity that pertain to optimal serum antibody responses, so that they may be monitored during clinical trials of candidate AIDS vaccines in humans. Recently, a human vaccine trial in which healthy, uninfected volunteers were primed with a gp160 recombinant vaccinia virus and boosted with purified rgp160 produced one of the strongest vaccine-induced, serum antibody response to HIV-1 envelope glycoproteins in humans to date $(40,44)$. In the present study, sera from these volunteers were evaluated for neutralizing and binding/fusion-inhibition antibodies, and for the epitopes or regions of gp160 responsible for these functional activities.

Boosting with rgp160 elicited relatively high titers of HIV1-specific antibodies as measured by IFA in sera from all 11 vaccinees evaluated (Table $I$ ). This is in agreement with the appearance of strong Western blot and ELISA reactivities observed previously (40). Boosting also resulted in the appearance of neutralizing antibodies in five of the vaccinees as measured in the MT-2 cell assay (Table I). Sera from the same vaccinees, and from three others, had neutralizing antibodies in an AA5-cell assay, and were reactive with the V3 loop in a peptide ELISA (40). The inability to detect neutralizing antibodies in the other three sera using our MT-2 cell assay probably reflects the low titer of antibodies present in these samples. Four of four neutralizing sera tested here became completely or nearly completely ineffective in the presence of a synthetic peptide corresponding to the V3 loop, but not in the presence of synthetic peptides to two other regions of the gp160 molecule (Table II). These results indicate that neutralizing antibodies induced by rgp 160 boosting were restricted and directed primarily against the V3 loop.

An important human immune response to native, intact HIV-1 is directed against the CD4 binding site of gp 120. These 

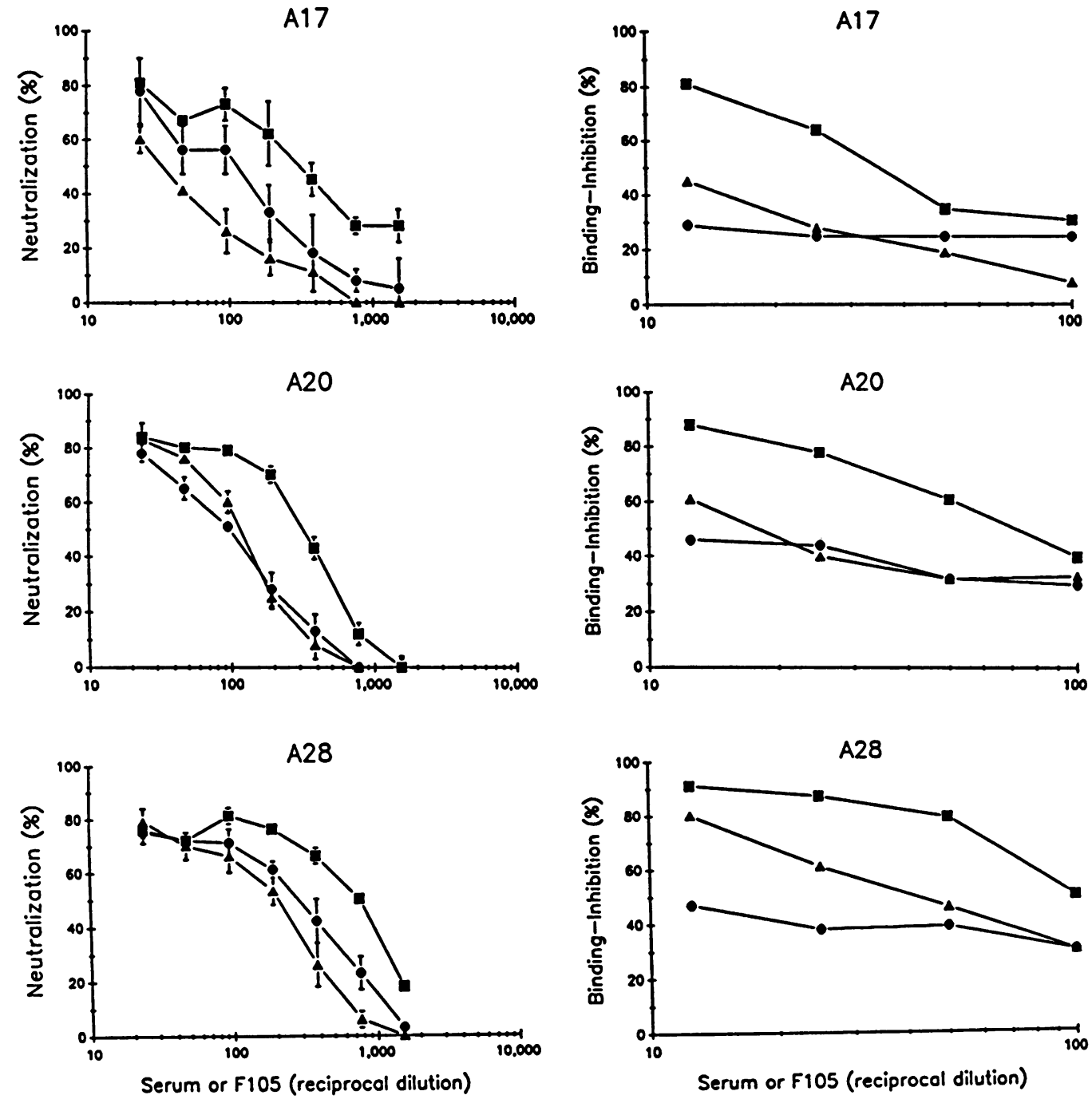

Figure 2. Combination effects with vaccinees' sera and humAb F105 on HIV-1 IIIB neutralizing and binding/fusion-inhibition activities. Eight dilutions of serum and F105 were evaluated alone and together for neutralizing activity (left), while four dilutions were evaluated alone and together for binding/fusion-inhibition activity (right). Results of neutralizing activity are expressed \pm SD of three replicates. Percent neutralization is the percentage of cells that were protected from viral-induced CPE. Binding/fusion-inhibition values are expressed as the average of duplicate assays, where the percent binding/fusion-inhibition activity is represented as the percent reduction in the amount of virus found associated with MT-2 cells after washing. The total amount of cell-associated virus ranged from 170 to $190 \mathrm{pg} \mathrm{p} 24 / \mathrm{ml}$ in the absence of blocking antibodies. Filled triangles, vaccinee's serum; filled circles, F105; filled squares, vaccinee's serum + F105. antibodies block gp120-CD4 binding and neutralize diverse strains of HIV-1 in vitro (20-22, 27-31). Hence, it would be desirable to elicit these antibodies by vaccination. The neutralizing sera evaluated here were previously shown to block radiolabeled gp1 20 from binding to $\mathrm{CD}^{+}$cells (40) and, although the regions or epitopes responsible for this activity were not identified, it seems likely that they were directed against the CD4 binding site of gp120. However, the fact that the majority of neutralizing activity was blocked by a synthetic peptide corresponding to the V3 loop of gp120 (Table II) suggests that antibodies to the CD4 binding site did not contribute significantly to neutralization.

Efforts to evaluate HIV-1 binding/fusion-inhibition antibodies were made here using a method more representative of natural conditions, where an assay was developed to detect antibodies capable of blocking whole virus particles from binding or fusing to viable cells. This assay differed from the radiolabeled gp1 20 assay in that gp120 was in its native, multimeric form attached to gp41 $(52,53)$, and was capable of mediating fusion owing to the presence of gp41 and an intact viral membrane (14-17). It was determined that boosting elicited HIV-1 binding/fusion-inhibition antibodies in all 11 volunteers and that much of this activity could be removed by a synthetic peptide corresponding to the V3 loop, indicating that these antibodies were V3 loop-specific (Table I). The portion of activity directed against the V3 loop probably represented fusion-inhibition activity because the V3 loop is not known to participate in binding (14-17). In fact, the 24-amino acid V3 loop peptide used in these experiments contained the GPGRA sequence shown to be important for fusion $(16,17)$. It is likely that V3 loop-reactive antibodies demonstrated activity in this assay because viral binding was secured by a fusion event that was blocked, and since gp1 20 is so loosely bound to gp41 (54), virus particles blocked in fusion were disengaged from cells by extensive washing. Because a portion of activity in some sera was not removed by the V3 loop peptide, additional antibodies were probably involved which recognized other sites on the gp160 molecule. These antibodies could have been against the CD4 binding site of gp120, as indicated by the binding-inhibition activity identified using a radiolabeled gp120 assay (40). The fact that much less binding/fusion-inhibition activity was V3 loop-specific in sera from infected individuals (Table I) indicates that infection induces a higher proportion of binding/ fusion-inhibition antibodies to other regions of the envelope glycoproteins of HIV-1.

Antibodies reactive with the CD4 binding site were further evaluated using a competitive antibody-binding assay, where sera from vaccinated volunteers were examined for an ability to block F105 from binding to its conformation-dependent epitope in the CD4 binding region of gp120. Antibodies in three of 
Table IV. Combination Indices for Data Obtained in HIV-I Neutralizing and Binding/Fusion-Inhibition Assays with Vaccinee's Sera and F105

\begin{tabular}{lcc}
\hline \multirow{2}{*}{ Serum } & \multicolumn{2}{c}{ Combination index calculated at 50\% activity if* } \\
\cline { 2 - 3 } & Mutually exclusive & Mutually nonexclusive \\
\hline Neutralization & & \\
A17 & 0.64 & 0.72 \\
A20 & 1.00 & 1.30 \\
A28 & 0.52 & 0.59 \\
Binding/Fusion-Inhibition & & \\
A17 & 0.27 & 0.27 \\
A20 & 0.38 & 0.42 \\
A28 & 0.33 & 0.34 \\
\hline
\end{tabular}

* Mathematical calculations were performed according to Chou and Chou (50) and are based on experimental results presented in Fig. 2. Antibodies having different modes or sites of action are considered mutually nonexclusive while antibodies having the same or similar action are considered mutually exclusive.

$C I<1$, synergistic; $C I=1$, additive; $C I>1$, antagonistic.

three neutralizing sera examined were not able to compete with F105 for gp120 binding (Table III). The CD4 binding site is composed of multiple epitopes that all overlap $(21,22)$, so it might be expected that all antibodies to this site will cross-inhibit binding of one another. The results obtained here, therefore, strongly suggest that putative antibodies to the CD4 binding site of gp120 responsible for the HIV-1 binding-inhibition activity detected previously (40), and confirmed here (Table I), were not abundantly present in these sera.

There have been reports that antibodies directed against the V3 loop and CD4 binding site of gp120 act synergistically together for gp 120 binding $(36,38)$ and for HIV-1 neutralization (36-39), suggesting that if antibodies to both regions of the gp 120 molecule were elicited by vaccination, individuals might be afforded better protection than if either type of antibody response were lacking. Synergism between antibodies to these two regions of gp120 was confirmed here, where vaccine-induced, V3 loop-specific human neutralizing antibodies were synergistic with F105 for neutralizing and binding/fusion-inhibition activity (Fig. 2 and Table IV). The presence of synergism is further evidence that antibodies to the CD4 binding site of gp120 were not prevalent in the vaccinees' sera, otherwise they should have resulted in an additive effect upon addition of F105. The fact that one serum, A20, had additive effects in neutralization assays might indicate that this individual had a higher titer of antibodies against the CD4 binding region, but their presence was not sufficient to compete with F105 for gp120 binding ( Table III). The poor representation of antibodies against the CD4 binding site of gp120 in sera from the remaining volunteers is consistent with the difficulty in eliciting these antibodies in immunized animals $(3,4)$, and their appearance late in infection (32-35).

In conclusion, neutralizing antibodies in vaccinees' sera after rgp160 boosting were mostly V3 loop-specific, where a portion of these antibodies might have been against a region of the V3 loop that participates in fusion. Because the V3 loop tends to be highly variable and strain specific $(23,24)$, this particular vaccine will probably induce only type-specific hu- moral immunity. New vaccines that optimize serum antibody responses to the more conserved CD4 binding site of gp120, in addition to the V3 loop, could potentially elicit broadly crossreactive antibody responses with stronger neutralizing activity and improved chances for providing protective immunity.

\section{Acknowledgments}

We thank Charlotte Emes and Jennifer Power for their technical assistance.

This work was supported by National Institutes of Health grants AI-05062 (B. S. Graham), AI-26926 (M. R. Posner), and AI-07387 (L. A. Cavacini).

\section{References}

1. Clark, S. J., M. S. Saag, W. D. Decker, S. Campbell-Hill, J. L. Roberson, P. J. Veldkamp, J. C. Kappes, B. H. Hahn, and G. M. Shaw. 1991. High titers of cytopathic virus in plasma of patients with symptomatic primary HIV-1 infection. N. Engl. J. Med. 324:954-960.

2. Daar, E. S., T. Moudgil, R. D. Meyer, and D. D. Ho. 1991. Transient high levels of viremia in patients with primary human immunodeficiency virus type 1 infection. N. Engl. J. Med. 324:961-964.

3. Girard, M., M.-P. Kieny, A. Pinter, F. Barre-Sinoussi, P. Nara, H. Kolbe, K. Kusumi, A. Chaput, T. Reinhart, E. Muchmore, et al. 1991. Immunization of chimpanzees confers protection against challenge with human immunodeficiency virus. Proc. Natl. Acad. Sci. USA. 88:542-546.

4. Berman, P. W., T. J. Gregory, L. Riddle, G. R. Nakamura, M. A. Champe, J. P. Porter, F. M. Wurm, R. D. Hershberg, E. K. Cobb, and J. W. Eichberg. 1990. Protection of chimpanzees from infection by HIV-1 after vaccination with recombinant glycoprotein gp1 20 but not gp160. Nature (Lond.). 345:622-625.

5. Fultz, P. N., P. Nara, F. Barre-Sinoussi, A. Chaput, M. L. Greenburg, E. Muchmore, M.-P. Kieny, and M. Girard. 1992. Vaccine protection of chimpanzees against challenge with HIV-1-infected peripheral blood mononuclear cells. Science (Wash. DC). 256:1687-1690.

6. Gardner, M. 1991. SIV vaccines: current status. The role of the SIV-macaque model in AIDS research. Vaccines (Cold Spring Harbor). 9:787-791.

7. Prince, A. M., B. Horowitz, R. W. Shulman, D. Pascual, I. Hewlett, J. Epstein, and J. W. Eichberg. 1991. Apparent protection of HIV infection by HIV immunoglobulin given prior to low-dose HIV challenge. In Vaccines 90. (F. Brown, R. M. Chanock, H. S. Ginsberg, and R. A. Lerner, editors). Cold Spring Harbor Laboratory, Cold Spring Harbor, NY. 347-351.

8. Prince, A. M., H. Reesink, D. Pascual, B. Horowitz, I. Hewlett, K. K. Murthy, K. E. Cobb, and J. W. Eichberg. 1991. Prevention of HIV infection by passive immunization with HIV immunoglobulin. AIDS Res. Hum. Retroviruses. 7:971-973.

9. Putkonen, P., R. Thorstensson, L. Ghavamzadeh, J. Albert, K. Hild, G. Biberfeld, and E. Norrby. 1991. Prevention of HIV-2 and SIVsm infection by passive immunization in cynomolgus monkeys. Nature (Lond.). 352:436-438.

10. Emini, E. A., W. A. Schleif, J. H. Nunmerg, A. J. Conley, Y. Eda, S. Tokiyoshi, S. D. Putney, S. Matsushita, K. E. Cobb, C. M. Jett, et al. 1992. Prevention of HIV-1 infection in chimpanzees by gp120 V3 domain-specific monoclonal antibody. Nature (Lond.). 355:728-730.

11. Klatzmann, D., E. Champagne, S. Chamaret, J. Gruest, D. Guetard, T. Hercend, J.-C. Gluckman, and L. Montagnier. 1984. T-lymphocyte T4 molecule behaves as the receptor for human retrovirus LAV. Nature (Lond.). 312:767768.

12. Dalgleish, A. G., P. C. L. Beverly, P. R. Clapham, D. H. Crawford, M. F. Greaves, and R. A. Weiss. 1984. The CD4 (T4) antigen is an essential component of the receptor for the AIDS retrovirus. Nature (Lond.). 312:763-767.

13. Veronese, F. M., A. L. DeVico, T. D. Copeland, S. Droszland, R. C. Gallo, and M. G. Sarngadharan. 1985. Characterization of gp41 as the transmembrane protein coded by the HTLV-III/LAV envelope gene. Science (Wash. DC). 229:1402-1405.

14. Rusche, J. R., K. Javaherian, C. McDanal, J. Petro, D. L. Lynn, R. Grimaila, A. Langlois, R. C. Gallo, L. O. Arthur, P. J. Fischinger, et al. 1988. Antibodies that inhibit fusion of human immunodeficiency virus-infected cells bind a 24-amino acid sequence of the viral envelope, gp120. Proc. Natl. Acad. Sci. USA. 85:3198-3202.

15. Skinner, M. A., A. J. Langlois, C. B. McDanal, J. S. McDougal, D. P. Bolognesi, and T. J. Matthews. 1988. Neutralizing antibodies to the immunodominant envelope sequence do not prevent gp120 binding to CD4. J. Virol. 62:4195-4200.

16. Page, K. A., S. M. Stearns, and D. R. Littman. 1992. Analysis of mutations in the V3 domain of gp 160 that affect fusion and infectivity. J. Virol. 66:524-533. 
17. Grimailia, R. J., B. A. Fuller, P. D. Rennert, M. B. Nelson, M-L. Hammarskjold, B. Potts, M. Murray, S. D. Putney, and G. Gray. 1992. Mutations in the principal neutralization determinant of human immunodeficiency virus type 1 affect syncytium formation, virus infectivity, growth kinetics, and neutralization. J. Virol. 66:1875-1883.

18. Javaherian, K., A. J. Langlois, C. McDanal, K. L. Ross, L. I. Eckler, C. L. Jellis, A. T. Profy, J. R. Rusche, D. P. Bolognesi, S. D. Putney, and T. J. Matthews. 1989. Principal neutralizing domain of the human immunodeficiency virus type 1 envelope protein. Proc. Natl. Acad. Sci. USA. 86:6768-6772.

19. Olshevsky, U., E. Helseth, C. Furman, J. Li, W. Haseltine, and J. Sodroski. 1990. Identification of individual HIV-1 gp120 amino acids important for CD4 receptor binding. J. Virol. 64:5701-5707.

20. Ho, D. D., J. A. McKeating, X. L. Li, T. Moudgil, E. S. Daar, N. Sun, and J. E. Robinson. 1991. Conformational epitope on gp120 important in CD4 binding and human immunodeficiency type 1 neutralization identified by a human monoclonal antibody. J. Virol. 65:489-493.

21. Thali, M., U. Olshevsky, C. Furman, D. Gabuzda, M. Posner, and J. Sodroski. 1991. Characterization of a discontinuous gp 120 epitope recognized by a broadly neutralizing human monoclonal antibody. J. Virol. 65:6188-6193.

22. Thali, M., C. Furman, D. D. Ho, J. Robinson, S. Tilley, A. Pinter, and J. Sodroski. 1992. Discontinuous, conserved neutralizing epitopes overlapping the CD4-binding region of human immunodeficiency virus type $1 \mathrm{gp} 120$ envelope glycoprotein. J. Virol. 66:5635-5641.

23. Palker, T. J., M. E. Clark, A. J. Langlois, T. J. Matthews, K. J. Weinhold, R. R. Randall, D. P. Bolognesi, and B. F. Haynes. 1988. Type-specific neutralization of the human immunodeficiency virus with antibodies to env-encoded synthetic peptides. Proc. Natl. Acad. Sci. USA. 85:1932-1936.

24. Matthews, T. J., A. J. Langlois, W. G. Robey, N. T. Chang, R. C. Gallo, P. J. Fischinger, and D. P. Bolognesi. 1986. Restricted neutralization of divergen human T-lymphotropic virus type III isolates by antibodies to the major envelope glycoprotein. Proc. Natl. Acad. Sci. USA. 83:9709-9713.

25. LaRosa, G. J., J. P. Davide, K. Weinhold, J. A. Waterbury, A. T. Profy, J. A. Lewis, A. J. Langlois, G. R. Dreesman, R. N. Boswell, P. Shadduck, et al 1990. Conserved sequence and structural elements in HIV-1 principal neutralizing determinant. Science (Wash. DC). 249:932-935.

26. Javaherian, K., A. J. Langlois, G. J. LaRosa, A. T. Profy, D. P. Bolognesi, W. C. Herlihy, S. D. Putney, and T. J. Matthews. 1990. Broadly neutralizing antibodies elicited by the hypervariable neutralizing determinant of HIV-1. Science (Wash. DC). 250:1590-1593.

27. Kang, C. Y., P. Nara, S. Chamat, V. Caralli, T. Ryskamp, N. Haigwood R. Newman, and H. Kohler. 1991. Evidence for non-V3-specific neutralizing antibodies that interfere with gp 120/CD4 binding in human immunodeficiency virus 1-infected humans. Proc. Natl. Acad. Sci. USA. 88:6171-6175.

28. Steimer, K. S., C. J. Scandella, P. V. Skiles, and N. L. Haigwood. 1991. Neutralization of divergent HIV-1 isolates by conformation-dependent human antibodies to gp120. Science (Wash. DC). 254:105-108.

29. Tilley, S. A., W. J. Honnen, M. Racho, M. Hilgartner, and A. Pinter. 1991 A human monoclonal antibody against the CD4 binding site of HIV-1 gp120 exhibits potent, broadly neutralizing activity. Res. Virol. 142:247-259.

30. Posner, M. R., T. Hideshima, T. Cannon, M. Mukherjee, K. H. Mayer, and R. A. Byrn. 1991. An IgG human monoclonal antibody that reacts with HIV-1/gp120, inhibits virus binding to cells, and neutralizes infection. J. Immunol. 146:4325-4332.

31. Posner, M. R., L. A. Cavacini, C. L. Emes, J. Power, and R. Byrn. 1993. Neutralization of HIV-1 by F105, a human monoclonal antibody to the CD4 binding site of gp 120. J. Acquired Immune Defic. Synd. 6:7-14.

32. Berkower, I., G. Smith, C. Giri, and D. Murphy. 1989. Human immunodeficiency virus 1: predominance of a group-specific neutralizing epitope that persists despite genetic variation. J. Exp. Med. 170:1681-1695.

33. Robert-Guroff, M., M. Brown, and R. C. Gallo. 1985. HTLV-III neutralizing antibodies in patients with AIDS and AIDS-related complex. Nature (Lond.). 316:72-74.

34. Weiss, R. A., P. R. Clapham, J. N. Weber, A. G. Dalgleish, L. A. Lasky, and P. Berman. 1986. Variable and conserved neutralizing antigens of human immunodeficiency virus. Nature (Lond.). 324:572-575.

35. Profy, A., P. Salinas, L. Eckler, N. Dunlop, P. Nara, and S. Putney. 1990. Epitopes recognized by the neutralizing antibodies of an HIV-1-infected individual. J. Immunol. 144:4641-4647.
36. Thali, M., C. Furman, B. Wahren, M. Posner, D. D. Ho, J. Robinson, and J. Sodroski. 1992. Cooperativity of neutralizing antibodies directed against the V3 and CD4 binding regions of the human immunodeficiency virus gp 120 envelope glycoprotein. J. Acquired Immune Defic. Syndr. 5:591-599.

37. Potts, B. J., K. Field, Y. Wu, M. Posner, L. Cavacini, and M. WhiteScharf. 1992. Synergistic inhibition of HIV-1. J. Cell. Biochem. Suppl. 16E:70.

38. Tilley, S. A., W. J. Honnen, M. E. Racho, T-C. Chou, and A. Pinter. 1992 Synergistic neutralization of HIV-1 by human monoclonal antibodies against the V3 loop and the CD4-binding site of gp120. AIDS Res. Hum. Retroviruses. 8:461-467.

39. Buchbinder, A., S. Karwowska, M. K. Gorny, S. T. Burda, and S. ZollaPazner. 1992. Synergy between human monoclonal antibodies to HIV extends their effective activity against homologous and divergent strains. AIDS Res. Hum. Retroviruses. 4:425-427.

40. Graham, B. S., T. J. Matthews, R. B. Belshe, M. L. Clements, R. Dolin P. F. Wright, G. J. Gorse, D. H. Schwartz, M. C. Keefer, D. P. Bolognesi, et al 1993. Augmentation of HIV-1 neutralizing antibody by priming with gp 160 recombinant vaccinia and boosting with rgp160. J. Infect. Dis. 167:533-537.

41. Dolin, R., B. S. Graham, S. B. Greenberg, C. O. Tacket, R. B. Belshe, K. Midthun, M. L. Clements, G. J. Gorse, B. W. Horgan, R. L. Atmar, et al. 1991 The safety and immunogenicity of a human immunodeficiency virus type 1 (HIV-1) recombinant gpl60 candidate vaccine in humans. Ann. Int. Med. 114:119.

42. Keefer, M., R. Belshe, M. Clemens, B. Graham, L. Corey, D. Bolognesi, D. Stablein, W. Koff, and P. Fast. 1992. Safety and immunogenicity of a baculovirus derived HIV-1 IIIB recombinant gp 160 vaccine ( VaxSyn) in humans. Proc. Intl. Conf. on AIDS, 8th, Amsterdam. PoA2228 (Abstr.)

43. Graham, B. S., R. B. Belshe, M. L. Clements, R. Dolin, L. Corey, P. F Wright, G. J. Gorse, K. Midthun, M. C. Keefer, N. J. Roberts, Jr., et al. 1992 Vaccination of vaccinia-naive adults with human immunodeficiency virus type gp160 recombinant vaccinia virus in a blinded, controlled, randomized clinical trial. J. Infect. Dis. 166:244-252.

44. Montefiori, D. C., B. S. Graham, S. Kliks, and P. F. Wright. 1992. Serum antibodies to HIV-1 in recombinant vaccinia virus recipients boosted with purified recombinant gp160. J. Clin. Immunol. 12:429-439.

45. Miyoshi, I., I. Kubonishi, S. Yoshimoto, T. Akagi, Y. Ohtsuki, Y. Shiraishi, K. Nagata, and Y. Hinuma. 1991. Type C virus particles in a cord T-cell line derived by co-cultivating normal human cord leukocytes and human leukaemic T cells. Nature (Lond.). 294:770-774.

46. Montefiori, D. C., W. E. Robinson, S. S. Schuffman, and W. M. Mitchell. 1988. Evaluation of antiviral drugs and neutralizing antibodies against human immunodeficiency virus by a rapid and sensitive microtiter infection assay. $J$. Clin. Microbiol. 26:231-237.

47. Ratner, L., W. Haseltine, R. Patarca, K. J. Livak, B. Starcich, S. F. Josephs, E. R. Doran, J. A. Rafalski, E. A. Whithorn, K. Baumeister, et al. 1985. Complete nucleotide sequence of the AIDS virus, HTLV-III. Nature (Lond.). 313:277-284.

48. Hu, S.-L., S. G. Kosowski, and J. M. Dalrymple JM. 1986. Expression of AIDS virus envelope gene in recombinant vaccinia viruses. Nature (Lond.) 320:537-541.

49. Cochran, M. A., B. L. Ericson, and J. D. Knell. 1988. Use of baculovirus recombinants as a general method for the production of subunit vaccines. In Vaccines 87. Cold Spring Harbor Laboratory, Cold Spring Harbor, NY. 384-395.

50. Chou, J., and T. C. Chou. 1989. Dose-Effect Analysis with Microcomputers: Dose, Effect, Binding and Kinetics. Computer Software for the IBM PC Series. Biosoft, Cambridge, UK.

51. Chou, T. C., and P. Talalay. 1984. Quantitative analysis of dose-effect relationships: The combined effects of multiple drugs or enzyme inhibitors. Adv. Enzyme Regul. 22:27-55.

52. Schawaller, M., G. E. Smith, J. J. Skehel, and D. C. Wiley. 1989. Studies with crosslinking reagents on the oligomeric structure of the env glycoprotein of HIV. Virology. 172:367-369.

53. Earl, P. L., R. W. Doms, and B. Moss. 1990. Oligomeric structure of the human immunodeficiency virus type 1 envelope glycoprotein. Proc. Natl. Acad. Sci. USA. 87:648-652.

54. McKeating, J. A., A. McKnight, and J. P. Moore. 1991. Differential loss of envelope glycoprotein gp120 from virions of human immunodeficiency virus type 1 isolates: Effects on infectivity and neutralization. J. Virol. 65:852-860. 